\title{
A study on Hyperprolactinaemia and associated factors among women attending Gynecology outpatient department at a tertiary teaching hospital in West Bengal
}

\author{
Debajyoti Tapadar', Debjani Sen Gupta ${ }^{2}$ \\ ${ }^{1}$ Professor and Head, Department of Gynaecology and Obstetrics, Jagannath Gupta Institute of Medical Sciences \\ and Hospital, Budge Budge, Kolkata, West Bengal, India, ${ }^{2}$ Assistant Professor, Department of Community Medicine, \\ Calcutta National Medical College Kolkata, West Bengal. India
}

Background: Prolactin has multiple biological functions and hyperprolactinaemia is a common condition in clinical practice in both females and males. It has many etiologies and may present with variable symptoms to health care workers. Aims and Objectives: To study the various etiologies and clinical presentation of patients presenting with hyperprolactinaemia in a tertiary care medical college and hospital in West Bengal to aid in quick decision management. Materials and Methods: The current study was a cross-sectional study with follow up conducted over a period of one year in the Department of Gynecology and Obstetrics, Jagannath Gupta Institute of Medical College and Hospital. Following sample size calculation, a total of 1824 women were enrolled for the study of which 53 were found to have raised prolactin level (after following proper inclusion and exclusion criteria) They were subsequently further examined and followed up. Results: Majority of the subjects studied belonged to $20-29$ age group $(49.05 \%)$ followed by $30-39$ years age group $(35.85 \%)$. The most common cause of hyperprolactinaemia in our study were idiopathic $(24.53 \%)$ followed by drugs $(22.64 \%)$ and pituitary adenoma. Most of the patients with hyperprolactinaemia, presented with complain of infertility $(56.6 \%)$, menstrual abnormality $(50.94 \%)$ and galactorrhoea $(18.87 \%)$ in our study. Therapeutic drugs used for various reasons were one of the main cause of hyperprolactinaemia $(22.64 \%)$ and mainly due to use of proton pump inhibitor with prokinetics use. Conclusion: Hyperprolactinaemia is very much common in patients with infertility, menstrual abnormality or galactorrhoea and mostly are due to idiopathic or drug induced causes. With early initiation of treatment most of the causes and effects can be cured.

Keywords: Hyperprolactinaemia; Idiopathic Hyperprolactinaemia; Drug induced Hyperprolactinaemia; Infertility

\section{INTRODUCTION}

Prolactin is a pituitary-derived hormone that plays a pivotal role in a variety of reproductive functions. It is an essential factor for normal production of breast milk following childbirth. Furthermore, Prolactin negatively modulates the secretion of pituitary hormones responsible for gonadal function, including luteinizing hormone and follicle-stimulating hormone. An excess of prolactin, or hyperprolactinaemia, is a commonly encountered clinical condition. ${ }^{1} \mathrm{It}$ is the most common disorder of the hypothalamic-pituitary-axis. Patients typically present with hypogonadism, infertility or, in the case of macroadenomas, symptoms related to mass effect (headache and visual field defects). Management of this condition depends on the cause and on the effects, it has on the patient. Commonly 
cited indications for treatment of macroprolactinomas include infertility, hypogonadism, prevention of bone loss and bothersome galactorrhea. ${ }^{2,3}$ However, indications and modalities of treatment of hyperprolactinemia due to pituitary microadenomas are less well defined. ${ }^{2}$

An excess of prolactin above a reference laboratory's upper limits, or "biochemical hyperprolactinemia," can be identified in up to $10 \%$ of the population. ${ }^{1}$ The prevalence of hyperprolactinemia ranges from $0.4 \%$ in an unselected adult population to as high as $9-17 \%$ in women with reproductive diseases. Its prevalence was found to be $5 \%$ in a family planning clinic. ${ }^{4}$ Women with oligomenorrhoea, amenorrhoea, galactorrhoea or infertility, and men with hypogonadism, impotence or infertility must have serum prolactin levels measured. ${ }^{1}$ It is estimated at 9\% among women with amenorrhea, 17\% among women with polycystic ovary syndrome, $25 \%$ among women with galactorrhoea and as high as $70 \%$ among women with amenorrhea and galactorrhea. ${ }^{2}$ The prevalence is about $5 \%$ among men who present with impotence or infertility. ${ }^{1}$

Prolactin is a $23 \mathrm{kDa}$ polypeptide hormone (198 amino acids) synthesized in the lactotroph cells of the anterior pituitary gland. Its secretion is pulsatile and increases with sleep, stress, food ingestion, pregnancy, chest wall stimulation, and trauma. The main biological action of prolactin is inducing and maintaining lactation. However, it also exerts metabolic effects, takes part in reproductive mammary development and stimulates immune responsiveness. ${ }^{5.6}$

There are a variety of causes which can lead to hyperprolactinaemia. These include physiological causes like pregnancy, lactation, exercise or sleep. The pathological causes are broadly divided into three causes. Conditions affecting pituitary gland like tumors, conditions damaging hypothalamic-pituitary stalk and systemic disorders can all lead to hyperprolactinaemia. ${ }^{7}$ Drug-induced causes are one of the most common etiologies of hyperprolactinaemia that we come across in day-to-day practice.

Identifying the correct etiology helps the clinician to give the best therapy minimizing unnecessary procedures and medication prescription.

\section{Aims and objectives}

This cross-sectional observational study was conducted with the following objectives

1. Enumerate the various causes leading to raised prolactin level in serum

2. Find out the presenting features of cases of prolactinaemia to aid quicker diagnostic and therapeutic measures.

\section{MATERIALS AND METHODS}

The current observational study was conducted at Jagannath Gupta Institute of Medical sciences, Budge Budge, West Bengal in the Gynecology out- patient department for 12 months.

The sample size was calculated considering a prevalence of hyperprolactinaemia of $5 \%{ }^{4}$ sample size at confidence of $95 \%$, power $80 \%$ and allowable error $15 \%$ sample size was 1824 .

Sampling method: Total enumeration of all cases with eligibility criteria (who attended Gynecology and Obstetrics outpatient department were enrolled for a period of one calendar year from January 2019 to December 2019 till a sample size of 1824 was reached. A total of 1824 cases were tested for prolactin level. Of which 53 women were found to have raised prolactin levels, who were further interviewed and investigated. The evaluation of hyperprolactinaemia was undertaken as per standard protocol. A detailed drug exposure history was also undertaken. Biochemical and hormonal evaluation and pituitary imaging (if required) were done. When no definite cause could be attributed the case was labeled as idiopathic. Written and informed consent was taken from each subject. The study was pre-approved by the Institutional Ethical Committee of this institution. The data was analyzed using standard statistical methods. The graphs and tables were generated using Microsoft Excel 2007 software.

Inclusion criteria: The subjects whose had raised levels of prolactin were enrolled in this study.

Exclusion criteria: Previously diagnosed cases, patients with known physiological causes of hyperprolactinaemia such as pregnancy, lactation or recent history of stress or surgery were excluded from the study along with infertility due to male factors.

\section{RESULTS}

Most of the patients with hyperprolactinaemia had values $<50$ microgram/L (77.35\%) and only one patient (1.9\%) had values $>150$ microgram/L (Table 1).

Table 2 shows the age wise distribution of study population where it is seen that range extends from $18-48$ years with $49.05 \%$ being in the age bracket of $20-29$ years. The next age group of $30-39$ years constituted $35.85 \%$ of study population.

In Table 3 it is presented that infertility accounts for most frequent complaints established by history 
Table 1: Prolactin levels among study subjects

\begin{tabular}{lcc} 
Prolactin Level (25microgm/L) & Number of Patients & $\%$ \\
\hline$<50$ microgram/L & 41 & 77.35 \\
$51-150$ microgram/L & 11 & 20.75 \\
$>150$ microgram/L & 1 & 1.9 \\
\hline
\end{tabular}

Table 2: Age-wise distribution of study population

\begin{tabular}{lcc}
\hline Age & Number of Patients & $\%$ \\
\hline$<20$ & 4 & 7.55 \\
$20-29$ & 26 & 49.05 \\
$30-39$ & 19 & 35.85 \\
$>40$ & 4 & 7.55 \\
\hline
\end{tabular}

\section{Table 3: Distribution of common features of} hyperprolactenemia among study subjects

\begin{tabular}{lccc}
\hline Presentation & Present & Absent & Not Stated \\
\hline Infertility & $32(60.38 \%)$ & $6(11.32 \%)$ & $15(28.30 \%)$ \\
Menstrual & $27(50.94)$ & $23(43.40 \%)$ & $3(5.66 \%)$ \\
Disturbance & & & \\
Galactorrhea & $10(18.87 \%)$ & $12(22.63 \%)$ & $31(58.5 \%)$ \\
Headache & $8(15.09 \%)$ & $8(15.09 \%)$ & $37(69.81 \%)$ \\
Visual & $4(7.55 \%)$ & $11(20.75 \%)$ & $38(71.7 \%)$ \\
disturbances/ & & & \\
other pressure & & & \\
symptoms & & & \\
Dyspareunia & $5(9.43 \%)$ & $2(3.77 \%)$ & $46(86.8 \%)$ \\
Breast Tenderness & $2(3.77 \%)$ & $1(1.9 \%)$ & $50(94.34 \%)$ \\
Libido & $1(1.9 \%)$ & 0 & $52(98.1 \%)$ \\
\hline
\end{tabular}

$(60.38 \%)$ followed by menstrual disturbance $(50.94 \%)$ and galactorrhoea (18.87\%). More than one presenting symptoms like infertility, menstrual disturbance was recorded from each subject. Headache was present in $15.09 \%$ of cases and visual disturbances due to pressure symptoms was seen in one case $(7.55 \%)$.

Table 4 indicates the chief complaint which also supports the findings of Table 3 indicating infertility to be the most common presenting symptom at $56.6 \%$ followed by oligomenorrhoea, while heavy painful menstrual periods accounting for $7.54 \%$ cases.

Table 5 indicates that $58.49 \%$ of women have symptomatic duration of $<6$ months and sought treatment for infertility. Symptom duration of more than 6 to 12 months was seen in $(26.41 \%)$ of subjects.

Table 6 elucidate the causes of hyperprolactinaemia in these patients. The cause was unknown or idiopathic in 13 patients $(24.53 \%)$ followed by uses of medication which accounted for 12 cases (22.64\%). Polycystic ovarian disease and Hypothyroidism were identified as the cause in 9 patients (16.98\%) and in 8 patients (15.09\%) respectively. Pituitary microadenomas was found in 10 patients mainly

\begin{tabular}{lcc}
$\begin{array}{l}\text { Table 4: Clinical presentation of } \\
\text { hyperprolactenemia among study subjects }\end{array}$ \\
\hline Main Presentation & Number of Patients & $\%$ \\
\hline Infertility & 30 & 56.60 \\
Oligomenorrhoea/Amenorrhoea & 8 & 15.09 \\
Heavy Painful Periods & 4 & 7.54 \\
Recurrent Miscarriage & 2 & 3.77 \\
Headache/Visual Problem & 1 & 1.89 \\
Galactorrhea & 2 & 3.77 \\
Galactorrhea/Dyspareunia & 1 & 1.89 \\
Infertility/Hot Flushes & 1 & 1.89 \\
Dyspareunia & 1 & 1.89 \\
Irregular Painful Periods & 1 & 1.89 \\
Headaches/Breast Soreness & 2 & 3.77 \\
\hline
\end{tabular}

\begin{tabular}{|c|c|c|}
\hline Duration of Hyperprolactinaemia & Number of Patients & $\%$ \\
\hline$<6$ Months/Transient & 31 & 58.49 \\
\hline$>6$ Months -12 Months & 14 & 26.41 \\
\hline$>12$ Months -24 Months & 3 & 5.66 \\
\hline >24 Months-36 Months & 5 & 9.43 \\
\hline
\end{tabular}

\begin{tabular}{lcc}
\multicolumn{4}{l}{ Table 6: showing etiologies of } \\
hyperprolactinaemia among study population \\
\hline \multicolumn{4}{l}{ Cause of Hyperprolactinaemia } & Number of Patients & $\%$ \\
\hline Idiopathic & 13 & 24.53 \\
Hypothyroidism & 8 & 15.09 \\
drugs & 12 & 22.64 \\
PCOS & 9 & 16.98 \\
Pituitary adenoma & 10 & 18.87 \\
Renal failure & 1 & 1.89 \\
\hline
\end{tabular}

presenting with pressure symptoms (18. 87\%). Only 1 patient was diagnosed with renal diseases.

In Table 7 , the drugs associated hyperprolactinaemia in the study population. Among drugs causing hyperprolactinaemia, proton pump inhibitors (PPI)/H2 receptor blockers with or without prokinetics accounted for $46.15 \%$ of cases. Hyperprolactinaemia was seen in patients consuming antipsychotics/antidepressants in $30.77 \%$ of cases.

\section{DISCUSSION}

Hyperprolactinaemia is one of the most common endocrine disorders encountered in clinical practice. As discussed earlier, the cause could be as varied as pituitary tumors to drug-induced causes. The majority of women in this study presented with infertility, menstrual irregularity or other symptoms leading them to seek clinical help earlier.

Normal serum prolactin levels range from 5 and 25 microgram/Lt in females although physiological and diurnal 


\begin{tabular}{lcc}
\multicolumn{3}{l}{$\begin{array}{l}\text { Table 7: Showing therapeutic drugs causing } \\
\text { hyperprolactinaemia among study population }\end{array}$} \\
\hline Drugs causing Hyperprolactinaemia Number of Patients & $\%$ \\
\hline Anti-psychotic/Anti-depressants & 4 & 33.33 \\
Anti -hypertensives & 1 & 08.33 \\
PPI with prokinetics & 6 & 50 \\
Contraceptives & 1 & 08.33 \\
\hline
\end{tabular}

variations occur. ${ }^{1}$ As per the findings of the current study, most of the patients had values between 25 to 50 microgram/Lt.

The majority of population consisted of patients belonging to third decade $(49.05 \%)$ according to our study which is similar to prevalence reported by Zargar et al. ${ }^{8}$ This could be due to the fact that majority of patients gets married in this age group and are therefore more bothered about their reproductive function and seek clinical help.

Infertility, Menstrual irregularity and galactorrhoea were the predominant symptoms among women with hyperprolactinaemia. The incidence of galactorrhoea in our study was $18.9 \%$ in comparison to prevalence of $45 \%$ by Zargar et al., ${ }^{8}$ and 33\% by Horng-Yih O et al. ${ }^{9}$ Similarly, we found menstrual irregularity to be present in 50.94\% of women whereas Horng-Yih $\mathrm{O}$ et $\mathrm{al}^{9}$ had reported similar problem in $42 \%$ of patients. The incidence of galactorrhoea in women with hyperprolactinaemia varies among different reports and occurs in $20-80 \%$ of subjects according to the study by Frank KS et al., (galactorrhoea uncommon) and by Thorner MO et al., (galactorrhoea 79\% of cases). ${ }^{10,11}$ While galactorrhoea is the classic symptom of hyperprolactinaemia, it only occurs in less than half of such cases according to the study by Abha et al. ${ }^{12}$

However, majority of women in our study presented with Infertility either primary or secondary $(60.38 \%)$. According to the study by Poppe $\mathrm{K}$ etal., ${ }^{13}$ and Zollner $\mathrm{U}$ et al., ${ }^{14}$ hyperprolactinaemia adversely affects the fertility potential by impairing pulsatile secretion of $\mathrm{GnRH}$ (gonadotropin releasing hormone) and hence interfering with ovulation. ${ }^{13,14}$

Menstrual abnormalities were detected in about $57.6 \%$ of the primary infertility cases in a study done by Goswami B et al. ${ }^{15}$ In our study also many patients, presented with infertility have menstrual problems (51\%). Goswami B et al., ${ }^{15}$ who found a higher occurrence of hyperprolactinaemia (41\%) in the infertile women as compared to the controls $(15 \%)$ in accordance with our study where majority patients with hyperprolactinaemia presented with infertility $(60.38 \%)$.

Most of the patients according to our study $58.49 \%$ have duration $<6$ months and mostly came for treatment of infertility, followed by those with duration of more than 6 to 12 months $(26.41 \%)$.
Idiopathic cause is the most common cause of hyperprolactinaemia in our study $(24.53 \%)$ followed by drugs $(22.64 \%)$, pituitary microadenoma (18.87\%), PCOS and hypothyroidism.

In a study conducted by Malik et al., ${ }^{23}$ to delineate the causes of increased prolactin levels, they reported the most common causes were prolactinomas (17\%), transient hyperprolactinaemia $(14.6 \%)$ and drug induced hyperprolactinaemia (14.4\%). In the current study, transient hyperprolactinaemia due to idiopathic causes were the most common aetiology of hyperprolactinaemia and was diagnosed mostly in women being evaluated for infertility. Yet another study done by Ben-David M et al., ${ }^{16}$ documented a transient rise of prolactin in females during their midcycle; the rate rises to $94 \%$ in those with infertility, ranging between 25-75 ng/mL and usually lasting for 1-3 days.

Drug-induced hyperprolactinaemia was the second most common cause of hyperprolactinaemia in our study where as it was also second most common cause reported by Horng-Yih $\mathrm{O}$ et al., ${ }^{9}$ and Suliman et al. ${ }^{17}$ The most common drugs included Proton pump inhibitors (PPIs) and prokinetics in our study which is in good agreement with the study reported by Horng-Yih Oet al. ${ }^{9}$

According to study conducted by Vilar L et al. ${ }^{18}$ PCOS is a common disorder in young adults and contributes to $13-16 \%$ of all cases of hyperprolactinaemia which is similar to our study where hyperprolactinaemia due to PCOS contribute $16.98 \%$.

Fifteen percent of our patients also showed features of hypothyroidism. Some patients with primary hypothyroidism had moderate hyperprolactinemia. ${ }^{19,20}$ Long-term or inadequately treated primary hypothyroidism can cause pituitary hyperplasia that may mimic a pituitary tumour. Hyperprolactinaemia and enlargement of the pituitary gland due to thyroid failure can be reversed by treatment with L-thyroxine. ${ }^{21,22}$

Prolactin-secreting pituitary adenomas are relatively common cause of hyperprolactaenemia and account for $30-40 \%$ of all pituitary adenomas, nearly all of which are benign. Depending on its size, the adenoma itself may cause signs and symptoms, including visual field abnormalities, blurred vision, and headache. In our study $10(18.87 \%)$ patients have been diagnosed as pituitary adenoma (by CT scan), of which one patient had severe visual problem with pituitary macroadenoma.

Medications inducing hyperprolactinaemia constituted $14 \%$ of all cases in the study conducted by Azhar A. Malik et al., ${ }^{23}$ where most patients were on antipsychotics 
or anti-emetics. Vilar et al., ${ }^{18}$ reported a similar rate $(12 \%)$ in Brazil; however, the rate was much higher (45.9\%) in Scotland with rising prevalence during the last years of the study. ${ }^{18,24}$ In our study also medication was the cause in almost $22 \%$ cases and mostly due to PPIs with antiemetics and anti-psychotics. The exact PPIs brand name or trade name could not be elicited as patients had taken it without medical prescription. Among the antipsychotics/ anti-depressants two patients were on Citalopram and one on Paroxetine and Amitriptyline each with $>24$ months duration.

Usual treatment of hyperprolactinaemia were followed with cause directed therapy along with Cabergoline treatment.

\section{CONCLUSION}

Hyperprolactinaemia is very much common in patients with infertility, menstrual abnormality or galactorrhoea and mostly are due to idiopathic or drug induced causes. The cause of hyperprolactinaemia should always be thoroughly evaluated as treatment can prevent considerable morbidity associated with this state. Early diagnosis and effective treatment are quite rewarding.

\section{ACKNOWLEDGEMENT}

The authors are indebted to the staffs and faculty of the department of Gynecology and Obstetrics, Jagannath Gupta Institute of Medical Sciences and Hospital.

\section{REFERENCES}

1. Josimovich JB, Lavenhar MA, Devanesan MM, Sesta HJ, Wilchins SA and Smith AC. Heterogeneous Distribution of Serum Prolactin Values in Apparently Healthy Young Women, and the Effects of Oral Contraceptive Medication. Fertil Steril. 1987; 47:785-791.

https://doi.org/10.1016/S0015-0282(16)59165-1

2. Casanueva FF, Molitch ME, Schlechte JA, Abs R, Bonert V, Bronstein MD, et al. Guidelines of the Pituitary Society for the Diagnosis and Management of Prolactinomas. Clin Endocrinol. 2006; 65:265-273.

https://doi.org/10.1111/j.1365-2265.2006.02562.x

3. Gillam M, Molitch M, Lombardi $G$ and Colao A. Advances in the Treatment of Prolactinomas. Endocr Rev. 2006; 27:485-534. https://doi.org/10.1210/er.2005-9998

4. BillerBM, LucianoA, Crosignani PG, Molitch M, Olive D, Rebar R, etal. Guidelines for the Diagnosis and Treatment of Hyperprolactinemia. J Reprod Med. 1999;44(Suppl 12): S1075-S1084.

5. Benker G, Jaspers C, Häusler G and Reinwein D. Control of Prolactin Secretion. KlinWochenschr. 1990; 68:1157-1167. https://doi.org/10.1007/BF01815271

6. Halbreich U, Kinon BJ, Gilmore JA and Kahn LS. Elevated Prolactin Levels in Patients with Schizophrenia: Mechanisms and Related Adverse Effects. Psychoneuroendocrinol.
2003;28(Suppl 1): S53-S67. https://doi.org/10.1016/S0306-4530(02)00112-9.

7. Melmed S, Kleinberg D, Ho K. Pituitary physiology and diagnostic evaluation. In: Williams textbook of endocrinology. $12^{\text {th }}$ Edn. Philadelphia: WB Saunders Company 2011: pp 175-228. https://doi.org/10.1016/B978-1-4377-0324-5.00008-0

8. Zargar AH, Laway BA, Wani AI, Salahuddin M and Masoodi SR. Epidemiologic and etiologic aspects of primary infertility in the Kashmir region of India. Ferti and Ster. 1997; 65 (4): 637-643. https://doi.org/10.1016/S0015-0282(97)00269-0

9. Horng-Yih O, Shu-Hwa $\mathrm{H}$ and $\mathrm{Yu} \mathrm{EH}$. Aetiologies and clinical manifestations of hyperprolactinaemia in a medical center in southern Taiwan. J Intern Med Taiwan. 2004;15(1):19-24. https://doi.org/10.25179/tjem.2020-77992

10. Frank KS, Nabarro JDN and Jacobs HS. Prevalence and presentation of hyperprolactinaemia in patients with functionless pituitary tumors. Lancet. 1977; 1:1778-1780. https://doi.org/10.1016/S0140-6736(77)92959-2

11. Thorner $\mathrm{MO}$ and Besser GM. Bromocriptine treatment of hyperprolactinemic hypogonadism. Acta Endocrinol. 1978; 88(Suppl 216):131-146.

12. Majumdar A and Mangal NS. Hyperprolactinemia. J Hum Reprod Sci. 2013; 6: 168-175. https://doi.org/10.4103/0974-1208.121400

13. Poppe $\mathrm{K}$ and Velkeniers $\mathrm{B}$. Thyroid disorders in infertile women. Ann Endocrinol (Paris) 2003;64(1): 45-50. https://doi.org/10.1089/105072502320908330

14. Zollner U, Lanig K, Steck T and Dieti J. Assessment of endocrine status in patients undergoing in-vitro fertilization treatment. Is it necessary? Arch Gynecol Obstet. 2001;265(1):16-20. https://doi.org/10.1007/s004040000110

15. Goswami B, Patel S, Chatterjee M, Koner BC, Alpana S. Correlation of prolactin and thyroid hormone concentration with menstrual patterns in infertile women. J Reprod Infertil. 2009;10(3):207-212.

16. Ben-David M and Schenker JG. Transient hyperprolactinemia: A correctable cause of idiopathic female infertility. J Clin Endocrinol Metab. 1983; 57:442-444.

https://doi.org/10.1210/jcem-57-2-442

17. Suliman AM, Al-Saber F, Hayes F, Fiad T, Culliton M, Cunningham $S$, et al. Hyperprolactinaemia: analysis of presentation, diagnosis and treatment in the endocrine service of a general hospital. Ir Med J. 2000;93(3):74-76.

18. Vilar L, Fleseriu $M$ and Bronstein MD. Challenges and pitfalls in the diagnosis of hyperprolactinemia. Arq Bras Endocrinol Metabol. 2014; 58:9-22. https://doi.org/10.1590/0004-2730000003002

19. Honbo KS, van Herle AJ and Kellett KA. 1978 Serum prolactin levels in untreated primary hypothyroidism. Am J Med. 1978; 64(5): 782-787. https://doi.org/10.1016/0002-9343(78)90517-X

20. Molitch ME. Pathologic hyperprolactinemia. Endocrinol Metab Clin North Am. 1992; 21:877-901. https://doi.org/10.1016/S0889-8529(18)30193-2.

21. Ahmed M, Banna M, Sakati N and Woodhouse N. Pituitary gland enlargement in primary hypothyroidism: a report of 5 cases with follow-up data. Horm Res. 1989; 32:188-192. https://doi.org/10.1159/000181287

22. Keye WR, Yuen BH, Knopf RF and Jaffe RB. Amenorrhea, hyperprolactinemia and pituitary enlargement secondary to primary hypothyroidism. Successful treatment with thyroid 
replacement. Obstet Gynecol. 1976; 48:697-702.

23. Malik AA, Aziz F, Beshyah SA and Khaled M. Aetiologies of Hyperprolactinaemia: A retrospective analysis from a tertiary healthcare centre. Sultan Qaboos Univ Med J. 2019; 19(2): e129-e134.

https://doi.org/10.18295/squmj.2019.19.02.008
24. Soto-Pedre E, Newey PJ, Bevan JS, Greig N and Leese GP. The epidemiology of hyperprolactinaemia over 20 years in the Tayside region of Scotland: The Prolactin Epidemiology, Audit and Research Study (PROLEARS) Clin Endocrinol (Oxf). 2017; 86:60-67.

https://doi.org/10.1111/cen.13156

Authors Contribution:

DT - Research methodology and Manuscript writing; DS - Concept, Study design and Manuscript preparation.

Work attributed to:

Department of Gynaecology and Obstetrics, Jagannath Gupta Institute of Medical Sciences and Hospital, Budge Budge, Kolkata, West Bengal, India

Orcid ID:

Dr. Debajyoti Tapadar - (1) https://orcid.org/0000-0003-1983-9343

Dr. Debjani Sem Gupta - (D) https://orcid.org/0000-0002-2026-2660

Source of Support: None, Conflict of Interest: None 